\title{
Synthesis and Characterisation of Polyethersulfone Membranes Incorporated with Titanium Dioxide Nanoparticles for Xylitol Separation from Mixed Sugars Solution
}

\author{
Khalefa A. Faneer, ${ }^{1,2,3}$ Rosiah Rohani ${ }^{1,2^{*}}$ and Abdul Wahab Mohammad ${ }^{1,2}$ \\ ${ }^{1}$ Department of Chemical and Process Engineering, Universiti Kebangsaan Malaysia, \\ 43600 UKM Bangi, Selangor, Malaysia \\ ${ }^{2}$ Centre for Sustainable Process Technology (CESPRO), \\ Faculty of Engineering and Built Environment, \\ Universiti Kebangsaan Malaysia, 43600 Bangi, Selangor, Malaysia \\ ${ }^{3}$ Department of Environment Engineering, \\ High Institute for Comprehensive Professions, \\ Bent Baya, Wadi al-Ajal, Libya \\ *Corresponding author: rosiah@ukm.edu.my
}

Published online: 15 February 2017

To cite this article: Faneer, K. A, Rohani, R. \& Mohammad, A. W. (2017). Synthesis and characterisation of polyethersulfone membranes incorporated with titanium dioxide nanoparticles for xylitol separation from mixed sugars solution. J. Phys. Sci., 28(Supp. 1), 73-84, https://doi.org/10.21315/jps2017.28.s1.5

To link to this article: https://doi.org/10.21315/jps2017.28.s1.5

\begin{abstract}
Separating xylitol from xylose and arabinose, which can be achieved through the fermentation broth, is a challenging task due to their closed molecular weight. Several methods have been used for the separation including adsorption, crystallisation and membrane. The separation of xylitol from sugar mixture by using nanofiltration (NF) membrane is of particular interest in this work. NF membrane is proposed based on the range of molecular weight of the mixture components that falls in NF (200 to $\left.2000 \mathrm{gmol}^{-1}\right)$. A new and efficient NF membrane used for separating xylitol from its mixture was tailored from polyethersulfone (PES) and PES incorporated with titanium dioxide ( $\mathrm{TiO}_{2}$ ) nanoparticles (NPS) of $1 \mathrm{wt}$ \% via phase inversion method followed by heat treatment. These in-house membranes were subjected to a systematic analysis, and later, their separation performance was evaluated using xylitol mixed solution. Both membranes exhibited improvement in $\mathrm{Na}_{2} \mathrm{SO}_{4}$ salt rejection up to $77 \%$ and $65 \%$ for unmodified and modified membranes, respectively. $\mathrm{PES} / \mathrm{TiO}_{2}$ membrane showed hydrophilicity improvement in contact angle (from $80 \pm 4.95^{\circ}$ to $68.6 \pm 2.16^{\circ}$ ) and water flux performance had increased a little from 12 to $15 \mathrm{~L} / \mathrm{m}^{2} . h$. The separation of xylitol from sugars using $\mathrm{PES} / \mathrm{TiO}_{2}$ membrane showed better performance compared to pure PES membrane, where
\end{abstract}


the permeate flux of xylitol solution was found to increase from 4 to $7 \mathrm{~L} / \mathrm{m}^{2}$.h when the modified membrane was used. These results indicate that the modified membrane with $\mathrm{TiO}_{2}$ NPs could be potentially used for the targeted application.

Keywords: PES, xylitol, nanoparticles, nanofiltration membrane, separation performance

\section{INTRODUCTION}

Xylitol is categorised as a polyalcohol and it has caught more attention in recent research works due to its significant use in food, medicine and pharmaceutical industries. ${ }^{1}$ Xylitol has many benefits to human health such as its ease for metabolism, prevention of dental caries and as a food additives in chewing gum, soft drinks, beverages and in bakery products. ${ }^{2}$ Either lignocellulose or xylose is used as the main source of xylitol production. ${ }^{3}$ Xylitol could also be commercially obtained chemically by using catalyst, ${ }^{4}$ or biotechnologically by using fungi, bacteria or yeast. ${ }^{5}$

The separation performance of xylitol is a complicated process due to presence of impurities and this separation can be achieved by using different techniques such as: (1) crystallisation $(75 \%),{ }^{6}$ (2) adsorption $(60 \%),{ }^{7}$ or (3) membrane technology (82\%). ${ }^{8,9}$ Based on this, membrane technique is reported to have given the highest purity compared to others. Membrane technique is also becoming a promising technology because it has the potential for energy saving and higher purity. Further, utilising nanofiltration (NF) membrane in this technique has proven to be an effective technology for the removal of organic materials such as sugars and sugar alcohol depending on molecular weight of the sugars $(152.15-150.15 \mathrm{~g} / \mathrm{mol}){ }^{9,10}$

Additionally, according to the NF membrane hydrophilicity that could potentially minimise fouling, etc., NF is recommended to be used for separation of xylitol from sugars. ${ }^{9}, 11,12$ Many types of polymers have been reportedly used to fabricate NF and UF membrane such as polyamide (PA), polysulfone (PSF) and polyethersulfone (PES). ${ }^{13,14}$ Of all, PES has been chosen in this study due to its toughness and chemically endurance. ${ }^{15}$ PES polymers, which have ether groups and sulfone groups in their backbone chains, possess high glass transition temperatures $\left(T_{g}\right)$ and flexible chain in order to soften the polymer at a reasonable temperature due to the stiff sulfone groups and flexible ether linkages, respectively. 
PES structure differs within a range of $\mathrm{T}_{\mathrm{g}}$ about $190^{\circ} \mathrm{C}-230^{\circ} \mathrm{C}$. However, the main disadvantage of using PES is its low hydrophilicity (around $80^{\circ}$ ). Lack in the hydrophilicity in a polymer membrane may result in fouling to the membrane. ${ }^{16}$ Thus, the hydrophilicity of PES membrane could be modified by following different routes such as mixing with co-polymer, surface grafting, coating and adding ceramic fillers etc. ${ }^{17,18}$ Other than that, hydrophobic membrane could also be altered using nanoparticles (NPs) including $\mathrm{TiO}_{2}, \mathrm{SiO}_{2}, \mathrm{Al}_{2} \mathrm{O}_{3}$ and others to form hydrophilic membrane. ${ }^{19}$

Membrane hydrophilicity enhancement after addition of $\mathrm{TiO}_{2}$ nanoparticles have resulted in water flux improvement. ${ }^{20}$ Furthermore, when $1 \%-2 \%$ of $\mathrm{TiO}_{2}$ is incorporated with the pure membrane, the membrane porosity is increased, while when the ratio is increased to $3 \%$, the agglomeration of NPs occurred. ${ }^{21}$ Generally, the incorporation of NPs into the membrane influences the membrane characteristics significantly. The trade-off between permeability and selectivity of polymeric membranes could be solved by incorporating NPs. The presence of NPs has been found to alter the characteristics of the membranes' top layer, pore size, thickness, hydrophilicity and charge potential, and parameters related to the membrane structure such as the porosity and macrovoid morphology of the asymmetric support. ${ }^{22}$

Thus, this work is aimed to synthesise and characterise phase inversion PES NF membrane for xylitol separation application. The synthesised membrane was also incorporated with $\mathrm{TiO}_{2}$ NPs to enhance the membrane permeation properties for xylitol separation as well as maintaining other inherent properties of the polymers such as chemical, physical and morphological.

\section{EXPERIMENTAL}

\subsection{Materials}

Polyethersulfone (PES) granule (Goodfellow) was used as the membrane based polymer. Titanium dioxide $\left(\mathrm{TiO}_{2}\right)$ was used as nanoparticles $(99.5 \%, 20 \mathrm{~nm})$ (Nanoamor). N-methyl-2-pyrrolidone (NMP) with analytical purity $99.7 \%$ (Fluka, Germany) and distilled water were used as solvent and non-solvent, respectively. Xylitol, xylose and arabinose powder of 99\% (Acros Organic) were used as received for preparing synthetic sugar mixtures. 


\subsection{Membrane Preparation}

Phase inversion technique was used to fabricate the pure PES and $\mathrm{PES} / \mathrm{TiO}_{2}$ modified membranes. First, $1 \%$ of $\mathrm{TiO}_{2} \mathrm{NP}$ amount were dissolved in $10 \%$ of NMP at $60^{\circ} \mathrm{C}$ with $450 \mathrm{rpm}$ for $6 \mathrm{~h}$. Then, the $\mathrm{TiO}_{2}$ solution was added to dope solution containing PES (18\%) with residue NMP. Both dope solutions were stirred at the same preparation conditions for $6 \mathrm{~h}$. The homogenous solution formed was left $24 \mathrm{~h}$ for degassing and then it was sonicated for $1 \mathrm{~h}$ to avoid nanoparticle agglomeration. A certain amount of the solution was cast using a casting knife at $200 \mu \mathrm{m}$ thickness onto a glass plate at room temperature $\left(27^{\circ} \mathrm{C}\right)$. The cast membranes were immersed in distilled water for $2 \mathrm{~h}$ for solvent exchange, and then the distilled water was changed for complete solvent exchange. The fabricated membranes were then stored in distilled water at room temperature prior to heat treatment.

\subsection{Heat Treatment Procedure}

The PES fabricated membrane was dried for $24 \mathrm{~h}$ at room temperature prior to heating. The membrane samples were placed in the oven at $100^{\circ} \mathrm{C}$ for $20 \mathrm{~min} .{ }^{23}$ The heat-treated membrane was again kept in distilled water for further use.

\subsection{Membrane Characterisation}

\subsubsection{Contact angle}

The contact angle was measured to investigate the pure $\mathrm{PES}$ and $\mathrm{PES} / \mathrm{TiO}_{2}$ modified membrane's hydrophilicity. Both membranes were dried for $72 \mathrm{~h}$ prior to measurement. The Rame-Hart Model 200 standard contact angle goniometer was used with DROP image Standard Software with an accuracy of $60.10^{\circ}$. The medium used to measure the contact angle was deionised water and air at ambient temperature $\left(27^{\circ} \mathrm{C}\right)$.

\subsubsection{Membrane filtration performance}

The pure water flux and xylitol solution permeation of the PES and $\mathrm{PES} / \mathrm{TiO}_{2}$ membranes were carried out by a dead-end filtration in a pressure filtration unit (Sterlitech HP4750, Sterlitech Corporation, USA). Initially, both membranes were compacted at 22 bar until a steady water flux was achieved (more than $1 \mathrm{~h}$ ) using DI water prior to filtration experiments. The pure water flux (PWF) was measured at 4 bar by applying Equation 1. In order to minimise experimental errors, 5 samples were collected and the average flux value was reported. 


$$
\mathrm{J}_{\mathrm{w}}=\frac{\mathrm{V}}{\text { A.t }}
$$

where $J_{w}$ is the water flux $\left(\mathrm{L} / \mathrm{m}^{2} . \mathrm{h}\right), \mathrm{V}$ the permeate volume $(\mathrm{L}), \mathrm{A}$ the membrane area $\left(0.00146 \mathrm{~m}^{2}\right)$, and $\mathrm{t}$ the filtration time $(\mathrm{h})$.

Next, rejection of model mixture solution of xylitol was measured using the same apparatus. In order to investigate rejection of both membranes, $19.1 \mathrm{~g} / \mathrm{L}$ of xylitol mixture was used at 4 bar. $^{24}$ The rejection $(\mathrm{R})$ was calculated by using Equation 2:

$$
\mathrm{R}(\%)=\left(1-\frac{C p}{C f}\right) \times 100
$$

where $\mathrm{C}_{\mathrm{p}}$ and $\mathrm{C}_{\mathrm{f}}$ are concentrations of permeate and feed respectively.

The permeate concentrations $\left(\mathrm{C}_{\mathrm{p}}\right)$ of xylitol, xylose and arabinose were quantified using HPLC (Ultimate 3000, Thermo scientific, USA), under the following analytical conditions: RPM column (Rezex, dimension: $300 \times 7.8 \mathrm{~mm}$, USA), Refractive Index (RI) Detector (Refractomax 520, ERC, USA), DI water as mobile phase, $60^{\circ} \mathrm{C}$ temperature and $0.6 \mathrm{ml} / \mathrm{min}$ flow rate.

The membrane NF performances were also investigated via salt rejection study. It was done by subjecting both membranes (before and after heat treatment) to $20 \mathrm{mM}$ divalent salt rejection. The salt rejection was also calculated by using Equation 2 .

\section{RESULTS AND DISCUSSION}

\subsection{Membrane Characterisation}

\subsubsection{Contact angle}

The contact angle value of the membrane shows the material's hydrophilicity. As the hydrophobicity increases, the contact angle of the droplets with the surface increases. Surfaces with contact angles greater than $90^{\circ}$ are labelled as hydrophobic. ${ }^{25}$ Table 1 presents the results of contact angle and pore size of pure PES membrane and PES- $\mathrm{TiO}_{2}$ modified membrane. It is evident that the contact angle improved from $80 \pm 4.95^{\circ}$ to $68.6 \pm 2.16^{\circ}$ when $1 \%$ of $\mathrm{TiO}_{2}$ was incorporated with pure PES membrane. Furthermore, the membrane pore size has decreased from $7 \mathrm{~nm}$ to $5 \mathrm{~nm}$, while the membrane porosity has increased from $48 \%$ to $79 \%$ when the membrane was incorporated with $\mathrm{TiO}_{2}$ NPs (the measurement method 
of pore size was according to Guerout-Elford Ferry Equation). ${ }^{26}$ This is due to the fact that after $\mathrm{TiO}_{2}$ was added into the polymer doped solution, $\mathrm{TiO}_{2} \mathrm{NPs}$ will spread among PES chain segments. The chain segment cannot spread during membrane formation, and consequently, pore size diminished resulting smoother membrane surface and smaller contact angle. The same phenomenon was reported when the $\mathrm{TiO}_{2}$ was added to increase polyamide $/ \mathrm{TiO}_{2}$ membrane hydrophilicity. ${ }^{27}$ In this work, both contact angle values of $\mathrm{PES}$ and $\mathrm{PES} / \mathrm{TiO}_{2}$ membranes were less than $90^{\circ}$, thus, membranes are called as hydrophilic membranes; however, the

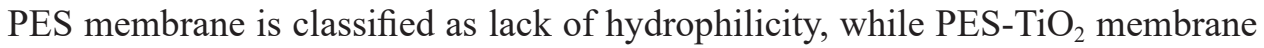
is more hydrophilic.

Table 1: The contact angle of PES and PES/TiO ${ }_{2}$ membranes.

\begin{tabular}{lccc}
\hline Membrane type & Contact angle $\left(^{\circ}\right)$ & Pore size $(\mathrm{nm})$ & Porosity (\%) \\
\hline PES $18 \%$ & $80 \pm 4.95^{\circ}$ & $7 \pm 0.5$ & $48 \pm 2$ \\
$\mathrm{PES} / \mathrm{TiO}_{2} 1 \%$ & $68.6 \pm 2.16^{\circ}$ & $5 \pm 1$ & $79 \pm 1$ \\
\hline
\end{tabular}

\subsubsection{Salt rejection study}

Prior to separation and filtration study, these in-house membranes were tested for salt rejection studies to confirm their NF range. Salt rejection was carried out to determine the membrane filtration performances towards divalent anions before and after heat treatment. It was done by testing the rejection of $20 \mathrm{mM} \mathrm{Na}_{2} \mathrm{SO}_{4}$ solution at 4 bar pressure. Table 2 showed $\mathrm{Na}_{2} \mathrm{SO}_{4}$ rejection before and after heat treatment. The divalent salt rejection of pure PES membrane increased from $48 \%$ to $77 \%$ while after incorporation of $\mathrm{TiO}_{2} \mathrm{NPs}$, the salt rejection also increased from $44 \%$ to $65 \%$. This result shows that the membranes fabricated are in NF-ranged as desired since the rejection in divalent salts are improved after heat treatment. The effect of adding multiwall carbon nanotubes (MWCNTs) NPs to pure PES membrane on the salt rejection has shown that the divalent rejection improved from $30 \%$ to $60 \%$ as $0.4 \%$ of MWCNTs NPs were added to the pure membrane. These results were used to confirm the nanofiltration performance of the membrane after adding NPs to the membrane. ${ }^{18}$

Table 2: $\mathrm{Na}_{2} \mathrm{SO}_{4}$ salt rejection of PES and $\mathrm{PES} / \mathrm{TiO}_{2}$ membranes.

\begin{tabular}{lcc}
\hline Membrane type & $\begin{array}{c}\text { Salt rejection before } \\
\text { heat treatment }(\%)\end{array}$ & $\begin{array}{c}\text { Salt rejection after } \\
\text { heat treatment }(\%)\end{array}$ \\
\hline PES $18 \%$ & $48 \pm 4$ & $77 \pm 2$ \\
$\mathrm{PES} / \mathrm{TiO}_{2} 1 \%$ & $44 \pm 2$ & $65 \pm 3$ \\
\hline
\end{tabular}




\subsubsection{Filtration and Separation Properties}

\subsubsection{Pure water flux}

The fabricated membranes were further tested for the water flux. Table 3 illustrates the pure water flux through the PES and PES/TiO ${ }_{2}$ membranes at 4 bar. The addition of $1 \mathrm{wt} . \%$ of $\mathrm{TiO}_{2} \mathrm{NPs}$ to the PES has no significant effect on the water flux, the flux increased from $12 \mathrm{~L} / \mathrm{m}^{2}$.h to $15 \mathrm{~L} / \mathrm{m}^{2}$.h. Meanwhile, the addition of NPs with lower concentration yielded greater presence of macrovoid, compared to the neat membrane, causing the water molecules to have a lower resistance to penetrate through the membrane, and thus giving higher flux. ${ }^{16}$ Therefore, it can be concluded that $\mathrm{TiO}_{2}$ incorporation in a pure PES membrane could increase the pure water flux as confirmed in the previous studies.

Table 3: The water and permeate flux of PES and $\mathrm{PES} / \mathrm{TiO}_{2}$ membranes.

\begin{tabular}{lcc}
\hline Membrane type & Water flux $\left(\mathrm{L} / \mathrm{m}^{2} . \mathrm{h}\right)$ & Permeate flux $\left(\mathrm{L} / \mathrm{m}^{2} . \mathrm{h}\right)$ \\
\hline $\mathrm{PES} 18 \%$ & $12 \pm 1$ & $4 \pm 1$ \\
$\mathrm{PES} / \mathrm{TiO}_{2} 1 \%$ & $15 \pm 2$ & $7 \pm 1$ \\
\hline
\end{tabular}

\subsubsection{Permeate flux}

The permeation study of xylitol mixture was carried out at 4 bar for $1 \mathrm{~h}$ to evaluate the membrane separation. To achieve this, a model solution of xylitol was used. Prior to this test, a synthetic solution of sugars was prepared following the same fermentation broth concentrations as reported by Mussatto et al. ${ }^{24}$ upon producing xylitol from sugarcane bagasse and the detail concentration used is shown in Table 4 . The results in Table 3 show the increasing flux on the modified membrane where the solution flux of pure PES membrane was observed at $4 \mathrm{~L} / \mathrm{m}^{2} . \mathrm{h}$, while $\mathrm{PES} / \mathrm{TiO}_{2}$ membrane's flux increased to $7 \mathrm{~L} / \mathrm{m}^{2}$.h.

Table 4: The feed solution concentrations.

\begin{tabular}{lccc}
\hline Component & Xylitol & Xylose & Arabinose \\
\hline Concentration (g/L) & 19.1 & 1.44 & 2.7 \\
Percentage (\%) & 82.2 & 6.2 & 11.6 \\
Molecular weight g/mol & 152.15 & 150.15 & 150.15 \\
\hline
\end{tabular}




\subsubsection{Xylitol solution rejection}

The rejection test was performed for investigating the effect of separating xylitol from mixed sugars on both membranes. This test was conducted at 4 bar. Based on Affleck, ${ }^{8}$ the use of high pressure will reduce xylitol rejection and is not recommended for this kind of separation. Same model solution (Table 4) was again used.

Initially, the calibration curve (Figure 1) for all sugar components at specific concentrations was constructed using HPLC method. The concentration of the main component (xylitol) was varied from 1.9 to $19.1 \mathrm{~g} / \mathrm{L}$. Based on the figure, the $\mathrm{R}^{2}$ values for all plots are found close to 1 , indicating that the linear equations for each of the components are reliable to be used in concentrations of xylitol, xylose and arabinose $(C p)$ seeking.

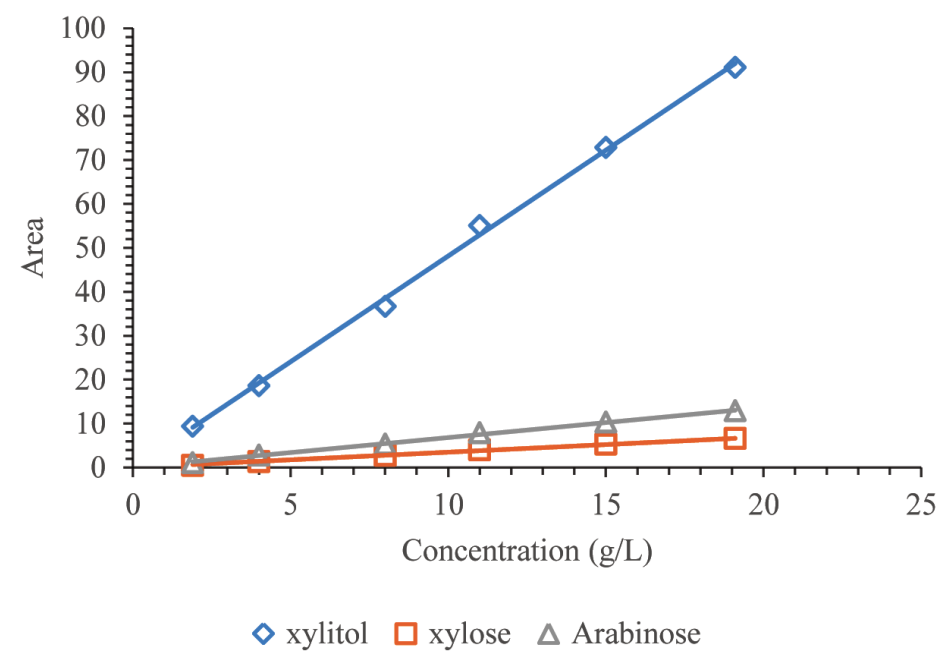

Figure 1: The standard curve of xylitol mixed solution.

The rejection of all sugar components after using both types of membranes are presented in Figure 2. As seen from Figure 2, xylitol rejection has increased from $54 \%$ to $56 \%$ when $\mathrm{TiO}_{2}$ NPs were incorporated in the PES membrane. The fact that the presence of $\mathrm{TiO}_{2}$ NPs may totally/partially plug the membrane pores is possibly one of the reasons for the increase in the rejection percentage. Another possible reason is that the increment of the hydrophilicity of the modified membranes have alleviated the adsorption of molecules on the top layer or pore wall of modified membranes, and further decreased the concentration polarisation and later decreased the mass transfer of solute through the membranes. ${ }^{16}$ 
Lin et al. ${ }^{16}$ have also reported on the role of the cake layer formation in the rejection of xylitol to a certain extent by suppressing the penetration of solute through the membrane. However, in this study, no cake layer was observed on the membrane surface during the filtration. There was also no flux decline along the filtration, which was possibly due to solution neutrality and the lower molecular weight of the components involved in the filtration. ${ }^{8}$ Hence, the former reasons (i.e., pore plugging, hydrophilicity increment) may have played the roles. On the promising view, both fabricated membranes showed the ability to separate the solution components that have same molecular weight.

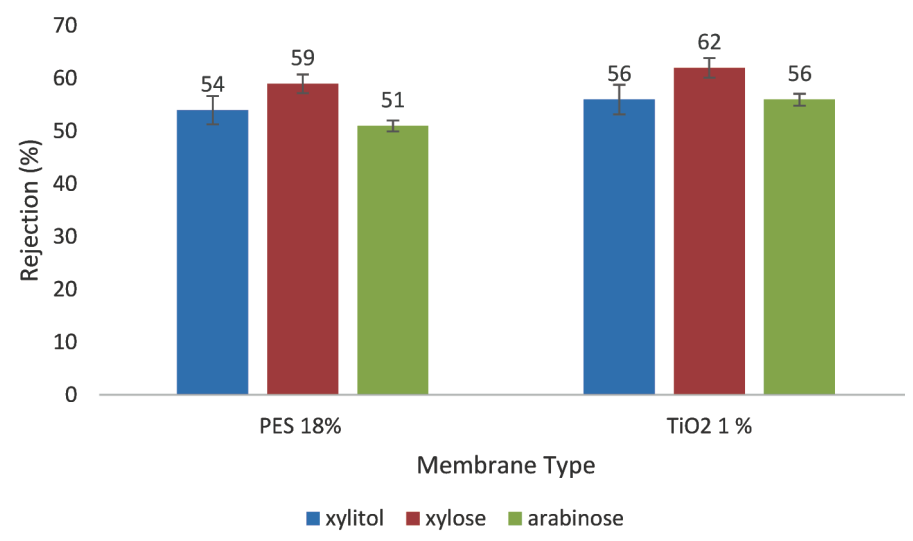

Figure 2: The xylitol mixture solution rejection of PES and $\mathrm{PES} / \mathrm{TiO}_{2} \mathrm{membranes}_{\text {(xylitol }}$ on the left bar, xylose middle, and arabinose right).

\section{CONCLUSION}

In conclusion, PES membranes incorporated with/without of $\mathrm{TiO}_{2} \mathrm{NPs}$ were successfully fabricated via phase inversion technique. The characterisations of the membranes with/without nanoparticles of $\mathrm{TiO}_{2}$ were investigated. The key conclusions are listed below:

- The heat treatment to the membranes brought them to be in NF from UF range

- $\mathrm{TiO}_{2}$ nanoparticles have affected the PES membrane properties where the contact angles have increased forward to be more hydrophilic

- The addition of $\mathrm{TiO}_{2}$ nanoparticles to PES membrane increased the membrane water flux

- Incorporation of NP has improved the xylitol permeation and rejection. The presence of NPs will increase the rejection percentage and enhance the solute separation performance 


\section{ACKNOWLEDGEMENTS}

The authors are thankful to the Long-term Research Grant Scheme (LRGS) for their financial support (LRGS/2013/UKM-UKM/PT/03), GUP/2016/086 from Universiti Kebangsaan Malaysia (UKM) and to the technical staff of the Department of Chemical and Process Engineering, UKM. First author Khalefa is grateful to the Ministry of High Education of Libyan government for scholarship.

\section{REFERENCES}

1. Mishra, D. K., Dabbawala, A. A. \& Hwang, J.-S. (2013). Ruthenium nanoparticles supported on zeolite $\mathrm{Y}$ as an efficient catalyst for selective hydrogenation of xylose to xylitol. J. Mol. Catal. A Chem., 376, 63-70, https://doi.org/10.1016/j.molcata.2013.04.011.

2. Rafiqul, I. \& Sakinah, A. (2012). A perspective bioproduction of xylitol by enzyme technology and future prospects. Int. Food Res. J., 19(2), 405-408.

3. Chuntranuluck, S., Vaithanomsat, P. \& Rodkamner, S. (2013). Xylitol obtained by fermentation of hydrolysate from steam explosion of Vetiveria zizanioides Nash. Kasetsart J. (Nat. Sci.), 47, 115-121.

4. de Albuquerque, T. L. et al. (2014). Biotechnological production of xylitol from lignocellulosic wastes: A review. Process. Biochem., 49(11), 17791789, https://doi.org/10.1016/j.procbio.2014.07.010.

5. Rivas, B. et al. (2006). Purification of xylitol obtained by fermentation of corncob hydrolysates. J. Agric. Food. Chem., 54(12), 4430-4435, https://doi.org/10.1021/jf053156x.

6. Sampaio, F. C. et al. (2006). Xylitol crystallization from culture media fermented by yeasts. Chem. Eng. Process. Process. Intens., 45(12), 10411046, https://doi.org/10.1016/j.cep.2006.03.012.

7. Martínez, E. A. et al. (2015). Strategies for xylitol purification and crystallization: A review. Sep. Sci. Technol., 50(14), 2087-2098, https://doi. org/10.1080/01496395.2015.1009115.

8. Affleck, R. P. (2000). Recovery of xylitol from fermentation of model hemicellulose hydrolysates using membrane technology. Unpublished student paper, Virginia Polytechnic Institute and State University.

9. Murthy, G. et al. (2005). Concentration of xylose reaction liquor by nanofiltration for the production of xylitol sugar alcohol. Sep. Purif. Technol., 44(3), 221-228, https://doi.org/10.1016/j.seppur.2005.01.009.

10. Sjöman, E. et al. (2006). Nanofiltration of monosaccharide containing solution to recover xylose. Desalin., 199(1), 348-349, https://doi.org/ 10.1016/j.desal.2006.03.082. 
11. Braeken, L. et al. (2005). Influence of hydrophobicity on retention in nanofiltration of aqueous solutions containing organic compounds. J. Membr. Sci., 252(1), 195-203, https://doi.org/10.1016/j.memsci.2004.12.017.

12. Goulas, A. K. et al. (2002). Purification of oligosaccharides by nanofiltration. J. Membr. Sci., 209(1), 321-335, https://doi.org/10.1016/S0376-7388(02) 00362-9.

13. Spahis, N., Dellali, M. \& Mahmoudi,H.(2012). Synthesis and characterization of polymeric/activated carbon membranes. Procedia Eng., 33, 47-51, http://dx.doi.org/10.1016/j.proeng.2012.01.1175.

14. Zhao, W. et al. (2011). Modification of polyethersulfone membrane by blending semi-interpenetrating network polymeric nanoparticles. J. Membr. Sci., 369(1), 258-266.

15. Razali, N. F. et al. (2013). Optimisation of polyethersulfone/polyaniline blended membranes using response surface methodology approach. Desalin., 311, 182-191.

16. Lin, J. et al. (2015). Enhancement of polyethersulfone (PES) membrane doped by monodisperse Stöber silica for water treatment. Chem. Eng. Process. Process. Intens., 107, 194-205, https://doi.org/10.1016/j.cep.2015.03.011.

17. Zhao, C. et al. (2013). Modification of polyethersulfone membranes: A review of methods. Prog. Mater. Sci., 58(1), 76-150, https://doi.org/10.1016/j. pmatsci.2012.07.002.

18. Vatanpour, V. et al. (2011). Fabrication and characterization of novel antifouling nanofiltration membrane prepared from oxidized multiwalled carbon nanotube/polyethersulfone nanocomposite. J. Membr. Sci., 375(1), 284-294, https://doi.org/10.1016/j.memsci.2011.03.055.

19. Shen, J.-n. et al. (2011). Preparation and characterization of PES-SiO 2 organic-inorganic composite ultrafiltration membrane for raw water pretreatment. Chem. Eng. J., 168(3), 1272-1278, https://doi.org/10.1016/ j.cej.2011.02.039.

20. Shariatmadar, F. \& Mohsen-Nia, M. (2012). PES/SiO2 nanocomposite by in situ polymerization: Synthesis, structure, properties, and new applications. Polym. Compos., 33(7), 1188-1196, https://doi.org/10.1002/pc.22248.

21. Li, J.-F. et al. (2009). Effect of TiO 2 nanoparticles on the surface morphology and performance of microporous PES membrane. Appl. Surf. Sci., 255(9), 4725-4732, https://doi.org/10.1016/j.apsusc.2008.07.139.

22. Lin, J. et al. (2013). Nano-WS 2 embedded PES membrane with improved fouling and permselectivity. J. Colloid Interf. Sci., 396, 120-128, https://doi.org/10.1016/j.jcis.2013.01.028. 
23. Rahimpour, A. et al. (2009). The effect of heat treatment of PES and PVDF ultrafiltration membranes on morphology and performance for milk filtration. J. Membr. Sci., 330(1), 189-204, https://doi.org/10.1016/j. memsci.2008.12.059.

24. Mussatto, S. I. et al. (2006). A study on the recovery of xylitol by batch adsorption and crystallization from fermented sugarcane bagasse hydrolysate. J. Chem. Technol. Biotechnol., 81(11), 1840-1845.

25. Arkles, B. (2006). Hydrophobicity, hydrophilicity and silane surface modification. Gelest Inc. Retrieved from http://www.gelest.com/goods/pdf/ Hydrophobicity.pdf.

26. Feng, C. et al. (2004). Preparation and properties of microporous membrane from poly (vinylidene fluoride-co-tetrafluoroethylene) (F2.4) for membrane distillation. J. Membr. Sci., 237(1), 15-24.

27. Jin, L. et al. (2012). Synthesis of a novel composite nanofiltration membrane incorporated $\mathrm{SiO} 2$ nanoparticles for oily wastewater desalination. Polym. J., 53(23), 5295-5303, http://dx.doi.org/10.1016/j.polymer.2012.09.014. 